\title{
IMAGINANDO NUEVOS VÍNCULOS EN EL ANTROPOCENO: OTRAS CORRESPONDENCIAS E HISTORIAS ENTRE EL BOSQUE DE ALERCES, LAS TEJUELAS Y LOS HUMANOS
}

\author{
Imagining new linkages in the Anthropocene:other \\ correspondences and stories between larch forest, \\ shingles and humans
}

\author{
Pedro Pablo Achondo Moya \\ Universidad de Chile, Chile.pedro.achondo@ug.uchile.cl
}

RESUMEN

El artículo propone, a través de un ejercicio de imaginación, nuevas posibilidades de comprensión y relación entre la vida humana y lo otro-que-humano. La crisis profunda en la que estamos inmersos, conceptualizada en términos del Antropoceno requiere una reflexión sobre la vida. Reflexión que ya no puede ser solamente al modo humanista ni científico-técnico, sino que requiere dialogar con otras epistemologías para reinterpretar las materialidades y los vínculos que construyen la vida humana sobre el planeta. Para ello se toma el caso de la tejuela de alerce, la que proveniente de los bosques de la Cordillera Pelada e instalada en el sur de Chile y narrada en sus múltiples interacciones nos conducen a una amplitud del pensar, del sentir y del conocer, a fin de cuentas, a una comprensión distinta del territorio. Es decir, a una lectura que ayude a reconducir el tiempo presente y enfrentar la crisis socioambiental de la mejor manera posible o, al menos, de una manera donde la imaginación y la creatividad jueguen un papel fundamental en la trama que Ilamamos coexistencia. Se presentan dos historias para enriquecer lo teóricamente discutido, de manera de ver materializada la imaginación y estimular otras prácticas y nuevas comprensiones de las alianzas multiespecie.

Palabras clave: Antropoceno; tejuela de alerce; imaginación; historias; crisis socioambiental

\section{ABSTRACT}

The article proposes, through an exercise of imagination, new possibilities of understanding and relations between human life and the other-than-human. The deep crisis in which we are immersed, conceptualized in terms of the Anthropocene, requires a reflection on life. This reflection can no longer be just humanistic or scientific-technical, instead it needs a dialogue with other epistemologies in order to reinterpret the materialities and links that build human life on the planet. We select the larch tile to study those links. The larch tile, which comes from the forests of the Cordillera Pelada and remaining in southern Chile is narrated in its multiple interactions and it leads us to a broader thinking, feeling, and knowing. In other words, to a different meaning of the territory. This reading helps us to redirect the present time and to face the socio-environmental crisis in the best possible way. Or, at least, in a way where the imagination and the creativity might play a fundamental role in the plot that we called coexistence. Two stories are presented to enrich the theoretically discussed, in order to see the imagination materialize, and stimulate other practices and new understandings of multispecies alliances.

Key words: Anthropocene, larch shingle, imagination, stories, socio-environmental crisis

Recibido: 27 de marzo de 2021. Aceptado: 3 de mayo de 2021.

DOI: $10.32735 /$ S0719-5265202138327 


\section{Introducción}

La crisis socioambiental planetaria desafía el pensar, el decir y el imaginar. Varios son los autores que ya sea desde el posthumanismo como desde otras corrientes epistemológicas afines nos instan no solo a asumir el desafío de otros mundos posibles (De la Cadena \& Blaser, 2018; Escobar, 2020), sino también a romper o superar la forma unívoca y hegemónica de comprender la realidad ligada al logos y al saber técnico-científico. Este desafío puede ser asumido desde distintas ontologías, saberes e imbricaciones.

En este artículo presentamos las posibilidades que se abren a partir de una comprensión de la realidad que busca instalarse en otro parangón que el dualismo filosófico cartesiano y abordar la imaginación y el cuerpo sintiente como otros locus de pensamiento alternativos al logos racional. Queremos continuar algunas intuiciones de Ingold $(2012,2018)$ y de pensadores lúcidos de nuestro tiempo, como Haraway (2008, 2016, 2019), Tsing (2015, 2017) Tsing et. al. (2020) y Morton (2016, 2018, 2019), quienes se instalan en el problema socioambiental y filosófico para comprender las relaciones y entramados complejos de la vida en crisis. Cabe citar a Leff (2018), de este lado del planeta, quien da en el clavo -según nuestro pareceral afirmar que la crisis socioambiental es en el fondo una crisis de las categorías y conceptos con los que comprendemos el entorno y la vida en general. En sus palabras "la destrucción ecológica de la biósfera es un hecho filosófico" (Leff, 2018: 168).

Para ilustrar lo que deseamos mostrar, presentaremos el caso de la materialidad y correspondencias de las tejuelas de alerce del sur de Chile. Someramente caeremos en la cuenta de la compleja red de relaciones que se gestan a partir de la tejuela y como ella puede contarnos otras historias y abrirnos a otros territorios.

A partir de ello podremos, y es lo que esperamos, abrirnos a otras formas de relacionamiento y a la construcción de otros vínculos -más poéticos que empíricos, más simbólicos que objetivos y más sugerentes y dialogantes que obtusos- respecto de la vida no humana y las materialidades que conforman lo que denominamos territorio. Comenzaremos con una breve reflexión sobre el Antropoceno para situar a la tejuela de alerce y definir nuestra comprensión de ella; para luego pasar a las historias que eventualmente de ella pueden desprenderse. Como telón de fondo y pregunta guía se encuentra la necesidad de imaginar y generar otras maneras de relacionarnos humanos y otros-que-humanos en el marco de la crisis socioambiental y civilizatoria que habitamos.

Ambas historias necesitan ser contextualizadas, tanto en su génesis como en su desarrollo. La primera historia, Líneas, tiempos y huellas, inspirada sobre todo en las reflexiones de Tim Ingold, es producto del taller Estrategias Metodológicas para Territorialidades Enmarañadas, dictado durante el mes de noviembre de 2020 
por Paola Jirón y Walter Imilán en el marco del Núcleo Milenio Movilidades y Territorios (MOVYT) y ofrecido como taller en el Doctorado en Territorio, Espacio y Sociedad (D_TES) de la Universidad de Chile. Dicha historia imagina una posible conversación basada en el encuentro con una tejuela de líneas confeccionada por el autor en la cual se entrelazan las líneas humanas (de manos, biografías y arrugas) con las líneas no humanas de las vetas, las estrías y los anillos temporales contenidos en la madera de alerce. La segunda historia, Bóvedas y lo que queda del bosque, es producto del taller Teorías Feministas para Enfrentar Problemáticas Territoriales: Contando Historias desde la Mirada de Donna Haraway, también realizado en el D_TES por la profesora Paola Jirón, durante los meses de mayo y junio de 2020. En esta ocasión se comparte parte del relato de ficción donde se imagina un futuro multiespecie en el que el territorio habitable se reduce a grandes bóvedas. Desde allí se cuenta una historia enmarañada ligada al bosque de alerces y la tejuela como aquello que queda del bosque.

Ambas historias se alimentan de la experiencia en terreno del autor ligada a las tejuelas de alerce y al bosque, en particular el Parque Nacional Alerce Costero (PNAC) ubicado en la comuna de La Unión, Región de los Ríos; en la denominada Cordillera Pelada. Detrás de los textos lo que hay es una experiencia sensorial e investigativa en aquel bosque y un estudio e interés por las tejuelas y lo que ellas implican y concentran, en términos temporales, históricos, estéticos, biológicos y territoriales.

\section{El Antropoceno: limitaciones y aperturas}

Sin repetir lo ya conocido respecto del Antropoceno nos gustaría más bien enunciar algunas limitaciones y por sobre todo manifestar su potencialidad e interés para lo que nos convoca.

Comencemos afirmando que más allá de la denominación o concepto, el Antropoceno ya estaba entre nosotros. Una cosa es la realidad y otra es la conciencia -empírica, científica, cultural- del fenómeno. Si el Antropoceno, en cuanto era geológica, comienza con la era industrial y la consecuente Gran Aceleración (Morton, 2018; Lewis \& Maslin, 2015; Crutzen, 2002), o más bien la situamos en el inicio de la agricultura (Morton, 2016), o la datamos en torno al encuentro entre Europa y los pueblos de América (Lewis \& Maslin, 2015; Armiero, 2021), lo que se nos quiere decir es que nos referimos a una época eminentemente humana. A un tiempo, era o momento, donde el protagonismo humano ha generado una perturbación (Tsing et al., 2019) tal que la comprendemos como irreversible.

De esa forma el Antropoceno, y esto hace falta explicitarlo con más fuerza, denota una época de devastación y degradación. El Antropoceno pone, en tela de 
juicio al propio humano o la idea del humano que hemos construido y sobre la cual hemos levantado un mundo. Esta interesante reflexión merecería ser discutida y profundizada. Para lo que nos toca en este artículo valga afirmar que el Antropoceno, en cuanto concepto anti-antropocéntrico (Morton, 2016: 24) nos instala en una brecha, en una fisura ontológica y antropológica. ¿Quién es el humano del Antropoceno? ¿Quiénes realmente habitan el Antropoceno? ¿El homo consumidor, el homo económico, el homo extractivista, los desechados (Wasteocene, en Armiero, 2021)? ¿Es posible que la debacle socioambiental tenga sus raíces en la instalación de los primeros cultivos y la vida sedentaria?

El Antropoceno, al decir de Chakrabarty (2018) y de Ulloa (2017), posee bastantes más aristas conceptuales de las que coloquialmente se presentan. Es posible agruparlas si la discusión es sobre la responsabilidad, la que podríamos llamar de arista ética (Capitaloceno en Moore, 2016; Plantacionoceno en Latour et al., 2018; Wasteocene en Armiero, 2021). Luego, si la discusión versa sobre el activismo y movimientos socioambientales; que podríamos denominar de arista práctica o de la acción movilizadora (Gudynas, 2020; Gudynas et al., 2019; Poma, 2017; Svampa, 2019), pasando por una arista creativa o estética ligada a la idea del Chthuluceno de Haraway (2016), del Plantropoceno (propuesto por Myers, 2017, donde ella juega con las palabras pues habla de planthroposcene, escenas del Plantropoceno aludiendo a la dimensión estética y artística de la vida humana con/en/junto a las plantas) o incluso la interesante propuesta del Aeroceno ${ }^{1}$ de Saraceno (2018), donde se trabaja la idea de lo leve, del aire y el desplazamiento sin ningún tipo de energía fuera del mismo aire.

Es decir, si por un lado el es un tiempo 'largo' de profunda crisis y transformación producto de la presencia, acción y perturbación humana en el planeta, que hoy (desde los 2000) viene a irrumpir el pensamiento y la organización de la vida humana y más-que-humana; por otro lado, se constituye en un tiempo 'reciente' de honda creatividad, de una imaginación rupturista que más allá de la mera ficción ha llegado a desarmar la ciencia y desafiar el mundo. Pero hay que ser justos, hay mundos que hace milenios desafían al mundo; la diferencia es que la crisis se le presenta como un imperativo a la razón y la praxis que el mundo, hoy, no puede dejar pasar. Por eso es posible decir que el segundo Antropoceno es profundamente antipatriarcal, anticolonial, antineoliberal y antiglobalizador.

No obstante lo anterior, es menester comprender al Antropoceno a partir de otra arista, que con Ulloa (2017) podríamos denominar de territorial. Comprender la crisis socioambiental y sus consecuencias devastadoras solo en términos globales, planetarios o geológicos; sería un error. De alguna forma el Antropoceno se

\footnotetext{
${ }^{1}$ Ver https://aerocene.org/ y https://studiotomassaraceno.org/
} 
territorializa en cada región, en cada aldea, en cada geografía. Si tuviéramos que hilar fino, el Antropoceno no existe; lo que hay son manifestaciones de la perturbación humana en el entorno, las cuales se expresan de forma particular en cada zona o región, país y continente; sin, por supuesto, menospreciar la influencia y degradación a escala planetaria. No es lo mismo comprender el a partir de algunos pueblos amazónicos que situados en el corazón de la sociedad occidental urbana como puede ser New York o Londres; ni mucho menos pensarlo desde algún valle rural de África del sur o enfrentarlo a partir de la megasequía en Putaendo, zona central cordillerana de Chile. El Antropoceno se territorializa y de esa forma es posible comprenderlo en su complejidad y riqueza.

\section{Las tejuelas de alerce}

Los sectores altos de las Cordilleras de la Costa y de los Andes, entre las provincias de Valdivia y Palena $\left(40^{\circ}-42^{\circ} 30^{\prime} \mathrm{S}\right)$, en Chile, y localmente en áreas adyacentes de Argentina, se destacan por sus bosques de alerce (Fitzroya cupressoides). Se encuentran también en pequeñas poblaciones que lograron sobrevivir a los incendios entre Pargua y el noreste de Puerto Montt. Corresponde a una especie endémica de gigantescos árboles que se caracterizan por su longevidad, llegando a vivir más de 3.000 años (el alerce más antiguo datado consta de 4.058 años). Su madera -tono, textura, color, facilidad de uso- y dimensiones: tamaño y altura (45 metros de alto y unos 5 metros de diámetro), lo hacen una especie única. Debido a estas condiciones únicas, el alerce fue explotado sobre todo durante la década de 1950-1976. Hay vestigios de su uso mucho más antiguo (en torno al siglo XVI). Principalmente en durmientes para la línea férrea, postes para el alumbrado público, pilotes en las viñas de la zona central de Chile, madera para la construcción de viviendas y muebles, dentro y fuera del país y en la forma de tejuelas en las regiones del sur de Chile (Lara et al., 1999, Lara, 2016; Urbina, 2011).

La tejuela de alerce ha cautivado a artistas, artesanos, diseñadores y arquitectos, debido a la belleza estética, a la facilidad y versatilidad de su uso; llegando a constituirse en lo que algunos poéticamente y con mucha razón han llamado la piel del archipiélago de Chiloé (Ramos, 2018; De la Sotta \& Lares, 2019). Notoriamente, quienes ha aprendido el lenguaje de la madera han sido los propios tejueleros, trabajadores y artesanos dedicados al oficio del tejueleo, el arte de confeccionar las tejuelas de alerce. Oficio que solo es posible gracias a una especial comunicación con la madera, a un vínculo donde manos humanas y vetas de alerce entran en una conversación única. Este oficio, en lo que concierne al alerce, pues se confeccionan tejuelas de otras especies (lenga, ciprés, mañío, canelo, lingue, por 
ejemplo, Castillo Levicoy, 2015), se encuentra en vías de extinción desde que la Fitzroya cupressoides se decreta en 1976 como especie protegida y se prohíbe su tala.

La tejuela de alerce es un objeto, una materialidad en la que el alerce deviene luego del trabajo humano del tejuelero. Un objeto que puede variar en su tamaño y forma, pero básicamente se constituye en una tabla pequeña con terminaciones que varían en su diseño y forma (punta, arco, ángulos) generando un hermoso decorado y una armonía única en las edificaciones donde se utiliza (viviendas, iglesias, mausoleos en cementerios, pequeñas construcciones, otros). Como lo expresa De la Sotta (2019: 2):

La tejuela como objeto, en su dimensión material, corresponde a una tablilla plana, de sección transversal, rectangular, de 10 a $15 \mathrm{~mm}$ de ancho, largo promedio de $600 \mathrm{~mm}$, y un espesor entre 8 a $12 \mathrm{~mm}$. Elaborada en distintos tipos de madera (alerce, tepa, ciprés de las guaitecas entre otros), tiene dos extremos, uno que va oculto detrás del imbricado y otro expuesto como terminación decorativa. Si bien la cabeza, extremo opuesto (denominado borde de terminación de la tejuela), es comúnmente de borde rectangular, existe una variedad de formas para dar una expresión final al inmueble.

A partir de una reflexión en la línea de la ecología de los materiales (Ingold, 2012) y siguiendo la idea de las correspondencias, según la cual "es como si estuviésemos escribiéndonos cartas unos a otros $\mathrm{y}$, al hacerlo, trayendo nuestras vidas -junto con las vidas de quienes y de qué contamos- en una especie de confluencia" (Ingold, 2018: 12); habría que decir bastante más de la tejuela. ¿Acaso ella deja de ser alerce? ¿Cómo considerar el tiempo que habita en ella? ¿Qué territorios contiene una tejuela? ¿Qué historias va hilvanando la tejuela entre el humano, el bosque, el oficio, el monte y el clima; por ejemplo?

La tejuela desde esta perspectiva se va abriendo y nos va abriendo, en cuanto humanos, a otras formas de comprender las relaciones y el entorno. La crisis socioambiental, la devastación de los bosques y su regeneración (Skewes, 2019), el complejo Antropoceno de Tsing et. al. (2019), en cuanto entramado de historias, afecciones y materialidades; se nos presenta en forma de tejuela de alerce. Y desde allí nos cuenta otras historias. Historias familiares, historias comerciales, historias de edificaciones e historias ambientales. Cada tejuela estuvo albergada en un inmenso alerce; alerces que fueron testigos del paso del tiempo humano: en ello, la dendrocronología (Muñoz et al., 2020; Lara, 2016) nos ayuda a abrir nuestras ideas a otras concepciones temporales. El alerce contiene la huella del tiempo, de largos y gigantes incendios, de sequías y periodos climáticos que no conocemos ni registramos. El alerce nos deja la huella dendrocronológica de sus relaciones interespecie, da cuenta del ataque de parásitos y luchas por sobrevivir. Todo ello para 
luego, en forma de tejuela, formar parte de una Iglesia chilota y comenzar a albergar cantos y oraciones, súplicas y esperanzas.

La tejuela es una historia (Ingold, 2012, siguiendo a Barad, 2003). La tejuela es una huella espaciotemporal del clima, de los pequeños Antropocenos del sur de Chile, de la violencia forestal y el cariño tecnológico del artesano. Allí está todo contenido. Pájaros, nubes, lluvias, insectos, musgo. La tejuela de alerce, entonces, es leída como un libro, como un archivo socioambiental de vidas humanas y más-quehumanas en la malla de correspondencias (Ingold, 2018) e interacciones. La tejuela es una huella del Antropoceno, una línea de temporalidades más-que-humanas y de espacialidades múltiples. Aún es posible encontrar estas huellas en el Parque Nacional Alerce Costero, las que, en algunas zonas, en forma de cementerios madereros, nos narran no solo un oficio, sino vidas humanas: niños corriendo y siendo educados en plena cordillera pelada, familias cobijadas en un territorio habitado por alerces centenarios que al caer estremecían la tierra y hombres conocedores del bosque, de sus transformaciones, su suelo y rutas.

\section{Contar historias para nuevas relaciones}

La imaginación debe irrumpir en la era de los Antropocenos; debe abrirnos al pluriverso y conducirnos a futuros posibles, sostenibles, con sentido. Quisiéramos, en esta parte, contar dos historias. En la línea de las historias de Camille que narra Haraway (2016), también llamadas fabulaciones especulativas (Haraway, 2016); hacemos uso de la hermosa facultad imaginativa (Tsing, 2015) para pensar esos otros vínculos, esas nuevas alianzas multiespecie y esas otras territorialidades que nos permitan, tal vez, comprender la vida de otra forma para, así, generar relaciones distintas en tiempos de crisis planetaria. Para Coccia (2011), lo que hoy llamamos imaginación "no es sino una forma diminuta y derivada de esa facultad trascendental de la imaginación que vemos en acto en toda procreación y en el hecho mismo del viviente" (Coccia, 2011: 101). La imaginación tiene que ver con el acto mismo de ser, con las formas del habitar y con las relaciones que se establecen entre los cuerpos, humanos y con los otros-que-humanos.

La primera historia está inspirada en lo que Ingold (2018) denomina la vida de las líneas y las correspondencias que se nos presentan en los entramados humano-no humano. Se trata de salir, a pesar de las dificultades lingüísticas y conceptuales de esquemas del tipo sujeto-objeto, vivo-no vivo o sensible-no sensible. Probablemente situándonos en lo que Latour (2005) llama red o más bien en lo que Ingold (2018) denomina malla. Si para el primero las relaciones son $y, y, y$ (un ensamblaje), el segundo matiza afirmando el con, con, con (correspondencias). Seamos una red o una malla de interacciones, todos ejercemos y provocamos una 
agencia, solicitamos una respuesta, acentuamos un afecto. Todo se comunica con otros y lo otro, lo que a su vez modifica el todo. Esta malla (mesh, meshwork), a la cual también refiere Morton (2019), a veces traducida como trama (mesh), puede comprenderse como una sucesión compleja de correspondencias, de líneas que interactúan conformando una madeja de relaciones, afectos, emociones y percepciones. Estas breves historias, al modo de diálogos entre humanos, tejuelas, bosques de alerce y ambiente; quieren simplemente suscitar la necesaria creatividad e imaginación que el logos ha opacado. Para Morton (2019) y Haraway (2016) esta malla puede comprenderse desde la idea de simbiosis; una maraña tentacular de interdependencias humanas y no humanas, interacciones frágiles y en permanente tensión que nos desafían, a re-comprender las relaciones y las ideas que poseemos o con las cuales interpretamos los objetos.

\subsection{Historia 1: Líneas, tiempos y huellas}

¿Me diría qué ve usted aquí, en esta tejuela? Líneas, marcas, colores. Veo también el tiempo y veo lugares.

¿Cómo así? Es que Ud. me muestra esta tejuela y yo me acuerdo de mi viejo. De las horas que caminábamos al monte para encontrar esos alerces. No se imagina cómo eran, nada que ver que estos de aquí que tienen 300 o 400 años. Le estoy hablando de unos 70 años atrás. Yo era un niño. Y me acuerdo de los incendios del año 58, esos que duraron muchos meses, años. Los alerces de ese entonces daban miedo. Bueno, yo era un niño.

¿Si le pido que toque la tejuela, qué siente, qué le evoca, qué encuentra? Ud. sí que es raro, pero lo entiendo, sabe. Las tejuelas estas son una maravilla. Mire mis manos, llenas de marcas y cortes; huellas del trabajo. Yo soy así por el trabajo en el bosque y con las tejuelas de alerce. Toco las asperezas y vuelvo a estar en mi rancho trabajando con el hacha. Y las líneas que Ud. me dice, estas vetas son como las venas del árbol, aquí yo leo el tiempo y hasta siento el clima que hacía cuando trabajaba. Estas líneas son también las mías, las de mi familia y de la gente que trabajaba en esto.

Que duro parece que era el trabajo, la vida. Sí, muy dura, nada que ver que ahora. Y sabe, la añoro. Le digo eso sin arrepentirme. Horas bajo la lluvia, horas cargando los troncos inmensos junto a los animales, solos por allá en medio de los bosques. Ahí yo me sentía en paz. Feliz. Me va a hacer llorar usted. Es que estos recuerdos me emocionan y ahora queda tan poco. ¿Cómo no emocionarme pues? Después cercaron el monte, vinieron unas forestales y arrasaron con los árboles. Sabe que yo siendo niño, lloraba y sigo llorando.

Ahora que veo esta tejuela llena de líneas siento que son como las huellas digitales de la tejuela, del árbol. 
Se van cruzando con las suyas, ¿no cree? Las de sus manos y su rostro; las de su vida.

Sí. Somos el bosque, somos estas tejuelas nosotros. Llenos de asperezas, irregulares, curtidos. Trabajados también, por ellas, a través de ellas. Marcados por los alerces. Y sabe que después estas tejuelas son talladas como para darles una nueva identidad al ser instaladas en las casas. Como la huella digital de la familia. Impresionante. De alguna manera, sus manos, sus huellas, las huellas y marcas del árbol, las vetas de la tejuela, las líneas del tiempo y del territorio; todo eso se entrelaza y queda ahí, en la piel de una casa. ¿Cómo entender o que sé yo, interpretar todo eso?...

¿Me deja hacerle una última pregunta? ... ¿Dónde le gustaría morir?

Aquí mismo. Aquí, en este monte, acompañado de estos árboles y sus susurros. Cerquita de mi familia. Aquí nomás. Y cuando sea. Quizás yo ya me morí hace mucho tiempo.

Oiga vuelva, que tenemos que seguir conversando y tirando líneas.

4.2. Historia 2: Bóvedas y lo que queda del bosque ${ }^{2}$

¿Cuánto valen las tejuelas, señora?

Mire, tenemos 5.075 tejuelas en stock. Cada una vale 450 pesos más IVA, pero se las puedo dejar a 300 más IVA. Depende cuántas quiera llevar. Son de la medida tradicional: $60 \times 10$ y para que se haga una idea, 60 tejuelas cubren un metro cuadrado.

Fui testigo de ese diálogo por una grabación que dejó mi bisabuelo. Ese viejo parece que era un loco de las tejuelas de alerce. Siempre me pareció un poco excéntrico al escuchar sus historias. Pero de eso ya hace mucho tiempo. Apenas quedan tejuelas de alerce, supongo. Alguna que otra en un museo, quizás. Ya no hay bosques de alerce, ni mucho menos personas dedicadas al oficio de las tejuelas. No se venden, no se tallan, no se usan. Yo tengo esta, que como una reliquia familiar ha ido pasando de familia en familia, de casa en casa.

El último bosque de alerces fue arrasado por un inmenso incendio forestal hace ya más de 70 años. Hoy solo quedan restos, trazos, huellas de un pasado que por los videos y fotografías imagino bello y fascinante.

Mi bisabuelo plasmó gran parte de esa historia en uno de sus libros. Allí me enteré de la importancia de los territorios, de su significado para las comunidades humanas de aquellos años y, sobre todo, de las duras décadas que tuvieron que

${ }_{2}^{2}$ Este relato forma parte de una narración más extensa presentada el pasado 21 de abril de 2021 en el marco de la Conferencia Laboratorio "Constituir lo común" de NMAPA: Núcleo Milenio Arte Performatividad y Activismo. Ver https://www.nmapa.cl/conferencia-laboratorio-constituir-locomun-imaginando-una-nueva-vida-colectiva/ 
atravesar. Fueron años y años de desaparición. Hoy, resguardados en estos territorios encapsulados, protegidos por estas bóvedas de cristal no logro imaginar lo que sería vivir afuera.

En mi hogar somos 5. Dos árboles, una niña y un gato. Las familias recompuestas comenzaron antes de que yo naciera. Si no me equivoco hace unos 50 años atrás. No soy bueno para las fechas; mi memoria no es muy buena y en realidad ya no hay necesidad de recordar muchos datos, pues todo está almacenado de forma digital. Solo preguntamos y sabemos. Preguntamos y se nos dice. Los árboles son muy apreciados, cada familia debe al menos tener uno que cuidar, proteger y si tiene suerte, multiplicar. Eso sucede más en otras bóvedas. No las conozco, pero se me ha dicho que están especializadas en la regeneración de las plantas. De las pocas que pueden sobrevivir lo suficiente como para regenerarse. Yo amo mis árboles, con ellos compartimos agua, sol y espacio. Me siento bajo ellos y me imagino en los bosques del libro de mi bisabuelo. Él hablaba de árboles que llegaban a medir 45 metros. Me cuesta creerlo. Nunca he visto plantas tan grandes. Me parecen unos monstruos, con troncos inmensos. Lo imagino y siento un poco de miedo, como si el bosque hubiera sido un lugar sombrío y peligroso. Quizás esto de vivir en las bóvedas nos haya cambiado la forma en que entendemos el mundo. En mi bóveda somos unas 100 familias, todas multiespecie y recompuestas, es decir separadas de nuestros progenitores biológicos, mezclados según funciones, edades y tareas específicas en cada bóveda.

En Chile debe haber unas 1000 bóvedas, no más. El alza de temperatura en algunos lugares y la intempestiva nevazón en otros, hizo que mucha gente se fuera lejos, a otras latitudes, pero la gran mayoría no logró sobrevivir por largo tiempo; entre las sucesivas pandemias y la locura social que se desató producto de la gran crisis, comenzamos a crear estas bóvedas que con el tiempo se han perfeccionado logrando ser sitios bastante confortables. Lo reconozco. Pero también solitarios.

Escucho las grabaciones de mi bisabuelo y me dan ganas de salir, de conocer el afuera, de caminar por otros senderos, de tal vez respirar otros aires. Miro la tejuela de alerce que cuelga del arbolito e intento viajar hacia esos territorios de los que mi bisabuelo hablaba. Algunos los he oído, son parte de la historia de Chile. Chiloé, Osorno, Valdivia, Puerto Montt... Hoy ya no se usa eso de ponerle nombres a los lugares. Solo números y series. Me gustan los nombres. Mi bóveda es la 34TA. Pienso que estaba destinado a esta bóveda cuando veo apenas unos trazos del número 34 en la tejuela familiar.

Trato de imaginar cómo se hacían, cómo se sacaban de esos gigantes del bosque unas piezas tan pequeñas y simples, tan hermosas y rústicas. Me cuesta creer que seguían haciendo ese tipo de trabajos y con cuánto esfuerzo quizás, hace tan solo un siglo. No entiendo para qué. Según el relato de mi bisabuelo era un oficio bien 
valorado ese del tejuelero. Tuvo su tiempo, luego decayó porque al parecer ya no se podían cortar más árboles. Pero nunca desapareció del todo, sino hasta la hecatombe. Durante esas décadas todo decayó, todo cambió. Además, ya no había árboles que cortar ni troncos que trabajar. Mi tejuela está reluciente colgada de una de las ramas del arbolito de casa. Creo que es donde debe estar, con los suyos. Pero en alianza conmigo, con la niña y con el gato. Todos formamos un conjunto, una vida, un espacio. Todos nos entendemos así y sabemos que la vida depende de lo que el otro haga o deje de hacer. Si yo no alimento al gato y la niña, ellos con certeza tendrían que irse a otro hogar antes de morir. Si no riego los árboles estos se secarían y para el comité central de la bóveda es lo peor que un habitante puede hacer. Soy responsable de ellos, por ellos y ellos nos permiten respirar en este adentro, ellos nos resguardan y protegen, son ellos los que nos dan vida. Cada uno ofrece algo en la red simbiogenética de relaciones. Es hermoso.

Me cuesta entender cómo fue la vida antes de las bóvedas. Todas las tardes me siento a leer las memorias de mi bisabuelo y a caminar, con él, por los bosques de alerce. Intento sentir los troncos y las hojas, escuchar los pájaros y sentir el viento. ¡El viento! Eso es una de las cosas que me gustaría algún día conocer. En las bóvedas no hay viento. Miro la tejuela y me pregunto si ella sintió el viento, y si sería posible que el viento aún estuviera contenido en sus fibras y vetas.

-Esta tejuela es hermosa, debe tener unos 60 años de antigüedad. No sabría decir su origen, pero por el lugar donde estaba, casi seguro provenía de los alerces de la costa de Osorno, de la zona Huilliche de San Juan de la Costa. El corte corresponde a una punta de flecha de dos tercios, a pesar de que le falta la punta. Sin duda pertenecía a un tinglado en dos módulos, simétrico; con un traslape de medios. Se percibe la veta y la erosión del agua lluvia. Me aventuraría a decir que pertenecía a una construcción de dos módulos por hilada.

-Muchas gracias. Es interesante cómo el lenguaje de la tejuela puede ser descifrado, comprendido.

Sí, claro. Además, fíjate en cómo se comunicaba con el entorno, armonizando con el paisaje; no es cualquier tinglado ni módulo para cualquier construcción. La mano del tejuelero se nota en el corte de la tejuela; pero también la mirada del constructor y del arquitecto, y de los habitantes, por cierto. Todas esas miradas van haciendo que la tejuela se devele al territorio. A fin de cuentas, la tejuela es un árbol transformado y como tal sigue hablando a los pájaros, los hongos, el agua, los microorganismos y humanos.

Poco entendía de ese diálogo en las grabaciones de mi bisabuelo. Un especialista en tejuelas se entrevistaba con él. Un hombre de oficio y de estudio. Un maestro tejuelero y amante de la madera. Había algo fascinante en ese diálogo, algo desconocido en mi pequeño mundo. Lenguajes, conocimientos, arte y naturaleza se 
entrelazaban en una tejuela. ¿Cómo era posible que esta tejuela vieja y gastada, añosa, como un hueso hallado entre los escombros de un terreno baldío, pudiera decir tanto, albergar tanto?

¿Cómo era posible que aquella cosa que hoy colgaba de una ramita de mi árbol pudiera haber sido un refugio de tantas vidas?

Mi bisabuelo era de los que hablaban del Antropoceno; de las huellas y heridas que el Antropoceno había dejado en las comunidades y sus prácticas. El Antropoceno es como una prehistoria ya para nosotros, hijos de las bóvedas multiespecie. El Antropoceno ya inexistente pertenece a ese "afuera" tóxico y enrarecido. Hoy nos enseñan que las bóvedas son los verdaderos refugios de esperanza. Que el "afuera" es inviable y peligroso. Aquí podemos controlar la reproducción y producción de las especies; aquí podemos controlar la alimentación y el consumo de energía necesario. Aquí la vida no está sujeta a la incertidumbre ni mucho menos a las perturbaciones del antiguo Antropoceno. Nosotros hablamos de la era de la regeneración. Pero mi bisabuelo me quita el sueño y confunde mis ideas. El mundo me parece tan minúsculo cuando oigo sus grabaciones y leo sus escritos. Aprendo de bosques y construcciones y territorios discontinuos y comunidades humanas resistentes que celebran.

Del afuera solo tengo la tejuela. Ella representa algo que en las bóvedas dejamos de predicar: la libertad. Y con ella tengo a mi bisabuelo y sus memorias; $y$ no solo a él, también a las comunidades de tejueleros y a los constructores de casas e iglesias -en esos tiempos en que las hacían todavía- y tengo conmigo los paisajes y el mar, que solo he visto una vez y casi no recuerdo. Traigo conmigo los bosques y sus árboles infinitos y la tierra mojada de lluvia que en las bóvedas apenas se escucha; y tengo cerca las hojas bailando mientras caen, y el cariño y las risas y el gozo de levantar un refugio para una familia de las antiguas. No soy nostálgico, pero sí un soñador. Y la tejuela lo que me regala son los sueños de otras vidas, de otros tiempos, de otros parajes.

Cuando crezca la niña le entregaré la tejuela y tendrá que ser ella quien la cuide y reciba todas sus enseñanzas. Quizás sea ella quien la vuelva a plantar para que eche sus raíces en el afuera de esta bóveda.

\section{$* * *$}

Importa qué historias contamos, afirma Haraway (2016) y las cuenta (Haraway, 2019); como también importan los conceptos con los que pensamos y la manera en que construimos mundos. Las dos historias presentadas como un ejercicio de imaginación creativa y especulativa, alimentadas de un contexto socioambiental, de una reflexión teórica y de la experiencia territorial, nos permiten vislumbrar la posibilidad, por un lado, de representar los vínculos y relaciones de 
otras maneras y, por otro lado, dar cuenta de que la forma en que comprendemos el mundo y accedemos a él formatea lo que vemos, percibimos, sentimos y explicamos. Dar forma al mundo tiene que ver con representarlo. Coccia (2017), quien posee una profunda reflexión sobre las formas y la mixtura, ha indagado bastante en lo sensible (Coccia, 2011) y la manera en que la forma no es entendida como un añadido del fondo, sino como su parte fundamental. Aunque esto merezca ser debatido, cuando hablamos de relaciones, de vínculos y alianzas entre lo humano y lo otro-quehumano, la forma es el fondo. La manera en que las cosas suceden, aparecen, acontecen, dan cuenta de qué entendemos por ellas.

Dar forma al mundo, formar el pensamiento, puede constituirse en el momento lógico y fundamental para la construcción de alianzas multiespecie con sentido y futuro. El cambio climático, en este sentido, es una alerta al pensamiento, como hemos dicho, pero también a las formas -escalas, dimensiones, temporalidades, espacialidades- con las cuales comprendemos la realidad y lo que en ella sucede. Morton (2018), siguiendo a Heidegger, afirma que el ser no puede ser separado del aparecer. Necesitamos de una filosofía que nos permita pensar el aparecer de las cosas como hiperobjetos y procesos, al mismo tiempo. Es decir, que dé cuenta de las diferentes escalas y la complejidad de las relaciones e interacciones en la trama (Morton, 2018: 201), pero sin caer en una nueva objetivación de todo. En definitiva, comprender que no poseemos el control de los monstruos y fantasmas del Antropoceno (Tsing et al., 2017; Tsing \& Bubandt, 2020; Tsing et al., 2020) ni que podemos esconderlos en un más allá, porque, de hecho -y es lo que la crisis socioambiental nos ha venido a enrostrar- no hay algo como un más allá.

Formar el mundo es caer en la cuenta de que no hay un mundo como tal o, al decir de Morton (2018), asumir e integrar el fin del mundo, que no es otra cosa que el fin del mundo humano, tal como los humanos lo hemos concebido a partir de humanos y para humanos. Al mismo tiempo, consiste en comenzar a comprenderlo en términos plurales, interrelacionado y multitemporal. Se trata, afirmándonos en el locuaz y original pensamiento de Morton (2016, 2018, 2019) de asumir la vida como cosas y relaciones, como interacciones y como objetos, como temporalidades y como fenómenos, como procesos y como unidades. Comprender-nos en una trama de interacciones donde todos somos extraños y al mismo tiempo nos percibimos como familiarizados, humanos y otros-que-humanos. De ese modo la tejuela de alerce se configura de una forma completamente otra en su enmarañado aparecer. 


\section{Nuevas tejuelas y nuevas alianzas}

Entonces, ¿cómo es la tejuela de alerce de los Antropocenos? ¿Qué puede decirnos de la vida, del oficio del tejueleo y de las temporalidades que contiene? ¿Qué vínculos devienen y se entrelazan en la cosa llamada tejuela de alerce?

Hemos propuesto que el Antropoceno, en sus territorializaciones y versiones locales, como marco referencial temporal de la crisis socioambiental, nos impele a buscar formas de relacionamiento entre los humanos y el entorno, los objetos y la vida no humana, que nos permitan continuar con vida y que le den sentido a la coexistencia con todo lo que somos y nos rodea. Ello, como vimos, implica modificaciones en el pensar, en el concebir lo que llamamos mundo y en los vínculos que generamos con uno mismo, lo otro, los otros y el todo.

A partir del ejercicio de la imaginación coherente, posible y abierta; algo que sin duda realizan las artes y, en general, toda obra creativa, indagamos en relatos originales en los que, al modo de diálogos e interacciones, la tejuela de alerce deja de ser simplemente una tejuela de alerce y deviene en una concentrada maraña de referencias, temporalidades, territorios y dimensiones. Ella adquiere personalidad y elocuencia. Nos aventuramos a afirmar que siempre la ha tenido. Somos nosotros ahora, los humanos del Antropoceno, quienes comenzamos a re-descubrir lo que nos rodea y a mirar la vida animada e inanimada con otros ojos: con los ojos de la urgencia, con el mirar de la necesidad, con la atención de una nueva esperanza.

La tejuela de alerce se nos fue abriendo a partir de la conciencia y el conocimiento de su riqueza material, cultural, estética, arquitectónica y biológica. La tejuela se fue ampliando, derrumbando la hegemonía del logos, para dar lugar a otras maneras de comprenderla, interpretarla y conocerla. La tejuela devino en lo que también es: un alerce. Un Fitzroya cupressoides de quizás 300 años impregnado de lluvias y tierra, habitante de alturas y de la música propia de los bosques de alerce del sur de Chile en el Parque Nacional Alerce Costero. La tejuela, trabajada por manos humanas con quienes sin duda mantiene una relación única y estrecha continúa su periplo en la techumbre de una Iglesia en Chiloé. Ahora, cada vez que entramos a esa Iglesia, pequeña y poco visitada, con la reverencia de quien busca e implora, es el bosque de alerces quien nos recibe, es el canto del chucao y las gruesas raíces las que nos regalan su hospitalidad. La tejuela está allí, silenciosa y ruidosa, en su quietud de tejuela, acariciada como tejuela; observándonos a nosotros humanos del Antropoceno. Es el turno de que podamos re-descubrirlas en su profundidady riqueza, en su vitalidad y, así, percibir sus vibraciones (Bennett, 2010).

La tejuela en la techumbre proviene de un árbol centenario. Seguramente, algunas de ellas, recicladas de otras edificaciones, provienen de alguno que otro alerce milenario. Están allí ahora, a la intemperie, dejándose bañar por un tímido sol 
de junio.. Miles de años en un techo. Materialidades que han sido testigos de la transformación, degradación, destrucción, regeneración e investigación.

En cada tejuela van quedando las células que la piel del tejuelero dejó caer, en ellas se almacena la respiración del humano, los recorridos que tuvo que hacer para concluir su obra. Las tejuelas se llenan de aire y barro, de agua y el calor humano producto del esfuerzo y dedicación de los artesanos de la madera. Pero también son los pulmones humanos los que en cada inspiración dejan entrar células de alerce, partículas de tejuela, hiposujetos vivientes. La interacción se va transformando en relación, en coexistencia, en una nueva alianza que desafía nuestras categorías y conceptos. Ingold dirá que:

$\mathrm{Al}$ volverse diferente, una cosa podrá buscar distinguirse de otra sin que la otra se distinga de ella. Así, un rayo se ve contra el cielo de la noche, pero el cielo no se ve contra el rayo. La distinción es unilateral. Y esto, sugiere Deleuze, también pasa con el suelo y la línea. La línea, escribe, se distingue del suelo "sin que el suelo se auto distinga de la línea" (Ingold, 2018: 61).

¿Quién es la tejuela para su alerce? Un alerce entejuelado ¿Cómo ve la tejuela al alerce? Como algo completamente distinto, un extraño. ¿Y cómo continúa ese entramado de vínculos con los humanos, el clima y el territorio? La tejuela de la techumbre, ese árbol de tiempos y procesos más-que-humanos posee un trozo del Antropoceno, en ella, en su diminuta unidad espacial, se anida el cambio climático y la crisis ecológica. Allí, como un mapa de los ciclos y los quiebres nos regala un nuevo relato de la vida.

La sociedad humana y cada persona en particular puede formarse en una sensibilidad hacia las cosas, los artefactos, los pequeños cohabitantes del entorno y los gigantescos hiperobjetos (Morton, 2018) en los que navegamos el cosmos. Generar nuevas alianzas no es espontáneo. Los niños desde pequeños pueden aprender el arte de vivir en un planeta dañado (Tsing et al., 2017), amando las correspondencias entre todo lo que nos rodea, redescubriendo los vínculos de interdependencia y cuidado, maravillándose por y con la multidimensionalidad que habitamos: nubes, gases, hongos, bosques, la respiración que va y viene de unos a otros (Coccia, 2017), el sol que algún día será nuestro mayor enemigo, el arte de jugar, la poesía que nos embarga.

La tejuela de alerce es solo un objeto que si nos proponemos puede transformarse en un universo o, más bien, en puerta del pluriveso, pues de eso se trata lo por-venir... Un pluriveso de hermosas correspondencias, materialidades, vidas humanas y más-que-humanas. La tejuela puede devenir en un conjunto de historias que permitan animar la esperanza en un mundo degradado. 


\section{Conclusión}

En tiempos de toxicidad y malestar ecosocial las ciencias humanas, la filosofía y la técnica poseen la noble tarea de abrirnos a la esperanza. No solo la literatura o la religión, sino más que nunca el arte (estética), el pensamiento y los vínculos (ética y política) son los encargados de transportarnos epistemológicamente al pluriverso donde la vida continúe siendo valiosa y digna de ser vivida.

Una tejuela de alerce pareciera no ser nada más que una pieza en una techumbre o un trozo necesario para construir las murallas de alguna casa en el sur de Chile. En este artículo, haciendo eco de la elocuencia del posthumanismo, de la crítica antropológica al dualismo naturaleza-cultura y apoyado en reflexiones filosóficas en tiempos de catástrofe planetaria; hemos querido mostrar la riqueza de una materialidad que, al ser comprendida, interpretada y representada de otras maneras, puede, sin duda, abrirnos a otros mundos e interacciones conscientes. Más aún, nos permite re-descubrir las territorialidades que habitamos y re-encontrarnos con historias, formas de vida y sobrevivencia en los pequeños Antropocenos degradados y sufrientes.

El desafío se mantiene y queda la tarea de darnos forma, de formar-nos en, para y desde esta ecología de los materiales. Sigue de pie la urgencia por educar-nos más allá del logos y la racionalidad técnico-científica en tiempos del Antropoceno. Esta pincelada narrativa y especulativa puede ayudarnos a encauzar esta necesaria y preciosa labor.

No cabe duda de que la imaginación juega un rol fundamental. Ha llamado positivamente la atención en diversos espacios este ejercicio especulativo de contar historias, no solo imaginarlas, sino también compartirlas, co-costruirlas desde la escucha atenta con aquellos habitantes de los Antropocenos degradados y afectados. Ha despertado otras sensibilidades y activado hebras interiores un tanto adormecidas. La imaginación debe encarnarse, territorializarse y encorporarse de manera de devenir un posible: conceptos nuevos, palabras nuevas, narrativas otras que alimentarán prácticas y hábitos para el pluriverso. La pequeña tejuela, alerce centenario manufacturado, entrelazándose con lo humano desde lo otro-quehumano nos ha permitido abrir la imaginación y liberarla, al menos un poco y no sin errores, de la prisión epistemológica en que la vida se ha visto ahogada. Las dos historias podrán suscitar otras, ya no solo de tejuelas ni de bosques o de alerceros ni habitantes -todos ellos en sus múltiples correspondencias e interacciones-, de forma de continuar la construcción de los post-Antropocenos, una era donde lo tóxico y desechable (humanos y otros-que-humanos) no constituya lo preponderante. Eso esperamos. Eso imaginamos. 


\section{Agradecimientos}

El autor agradece el apoyo del Proyecto Fondecyt Regular $\mathrm{N}^{\mathrm{o}} 1190855$, en el cual se enmarca el presente artículo, que forma parte de la investigación Doctoral en Territorio, Espacio y Sociedad (D_TES) de la Facultad de Arquitectura y Urbanismo de la Universidad de Chile.

\section{Referencias}

Armiero, M. (2021). Wasteocene. Stories from the Global Dump. Cambridge: Cambridge University Press.

Barad, K. (2003). Posthumanist performativity: toward an understanding of how matter comes to matter. Signs, 28, 801-831.

Bennett, J. (2010). Vibrant Matter: A Political Ecology of Things. Durham: Duke University Press.

Castillo Levicoy, C. (2015) Distribución geográfica de la arquitectura vernácula con tejuela artesanal, región de Aysén, Conserva, 20, 7-21.

Coccia, E. (2011). La vida sensible. Buenos Aires: Marea Editorial.

Coccia, E. (2017). La vida de las plantas. Una metafísica de la mixtura. Buenos Aires: Miño y Dávila.

Chakrabarty, D. (2018). Anthropocene Time. History and Theory, 57(1), 5-32.

Crutzen, P. (2002). Geology of mankind. Nature, 415, 23.

De la Cadena. M. \& Blasser, M. (Eds.). (2018). A world of many worlds. London: Duke University Press.

De la Sotta, P. \& Lares, L. (2019). La Tejuela Chilota como Material Morfológico. Ponencia en Congreso de Enseñanza del Diseño, Palermo.

Escobar, A. (2020). Pluriversal Politics. The Real and the Possible. London: Duke University Press.

Haraway, D. (2008). When species meet. Minneapolis: University of Minnesota Press.

Haraway, D. (2016). Staying with the Trouble, Making kin in the Chthulucene. Durham/London: Duke University Press.

Haraway, D. (2019). El Patriarcado del Osito Teddy, Taxidermia en el jardín del edén. Buenos Aires: Sans Soleil Ediciones.

Ingold, T. (2012). Toward an Ecology of Materials. Annual Review of Anthropology, 41, 427-442.

Ingold, T. (2018). La vida de las líneas. Santiago: Ediciones Universidad Alberto Hurtado. 
Lara, A. (2016). Alerces: los viejos lentos del bosque. Revista Academia, 19, 30-37.

Lara, A., Fraver, S., Aravena, J.C. \& Wolodarsky-Franke, A. (1999). Fire and the dynamics of Fitzroya cupressoides (alerce) forests of Chile's Cordillera Pelada. Ecoscience, 6(1), 100-109.

Latour, B. (2005). Reassembling the Social: An introduction to Actor-NetworkTheory. Oxford: Oxford University Press.

Latour, B., Stengers, I., Tsing, A. \& Budant, N. (2018). Antropologist Are Talking About Capitalism, Ecology, and Apocalypse. Ethnos, 83(3), 587-606.

Leff, E. (2018). El fuego de la vida. Heidegger ante la cuestión ambiental. México: Siglo XXI Editores.

Lewis, S. \& Maslin, M. (2015). Defining the Anthropocene. Nature, 519.

Gudynas, E. (2020). Tan cerca y tan lejos de las alternativas al desarrollo. Planes, programas y pactos en tiempos de pandemia. Perú: RedGE.

Gudynas, E., Campanini, O. \& Gandarillas, M. (2019). Derechos y violencias en los extractivismos. Extrahecciones en Bolivia y Latinoamérica. Cochabamba: Lalibre Proyecto Editorial.

Morton, T. (2016). Dark Ecology, For a Logic of Future Coexistence. New York: Columbia University Press.

Morton, T. (2018). Hiperobjetos. Filosofía y ecología después del fin del mundo. Buenos Aires: Adriana Hidalgo editora.

Morton, T. (2019). La Pensée écologique. Paris: Zulma Essais.

Moore, J. (ed) (2016). Anthropocene or Capitalocene? Nature, History, and the Crisis of Capitalism. Oackland: PM Press.

Muñoz, A., Ferrero, M. E., Lucas, C. \& Aguilera-Betti, I. (2020). Meeting Report: A network for advancing dendrochronology, dendrochemistry and dendrohydrology in South America. Tree-ring Research, 76(2), 94-101.

Myers, N. (2017). From the Anthropocene to the Planthroposcene: Designing Gardens for Plant/People Involution. History and Anthropology, 28(3), 297-301.

Poma, A. (2017). Defendiendo territorio y dignidad. Emociones y cambiocultural en las luchas contra las represas en España y México. Campina Grande: Eduepb.

Ramos, F. (2018). Tejuelas de Chiloé. La piel del archipiélago. Santiago: Liberalia Ediciones.

Saraceno, T. (2018). Aerocene. Milano: Skira Editore.

Skewes, J. C. (2019). La regeneración de la vida en los tiempos del capitalismo. Otras huellas en los bosques nativos del centro y sur de Chile. Santiago: Ocho Libros. 
Svampa, M. (2019). Las fronteras del neoextractivismo en América Latina. Conflictos socioambientales, giro ecoterritorial y nuevas dependencias. Guadalajara: Calas.

Tsing, A. (2015). AURA's Openings. More-than-Human. AURA Working Papers Volume 1. Denmark.

Tsing, A. (2017). Le champignon de la fin du monde. Sur la possibilité de vivre dans les ruines du capitalisme. Paris: Les empêcheurs de penser en rond/La Découverte.

Tsing, A. \& Bubandt, N. (2020). Swimming with Crocodiles: Nature is avenged by prehistoric animal. Orion, 39(1), 35-42.

Tsing, A., Deger, J., Keleman Saxena, A. \& Zhou, F. (2020). Feral Atlas: The MoreThan-Human Anthropocene. Stanford University.

Tsing, A., Mathews, A. \& Bubadnt, N. (Eds.). (2019). Patchy Anthropocene: landscape structure, multispecies history, and the retooling of anthropology; an introduction to supplement 20. Current Anthropology, 60(20), 186-197.

Tsing, A., Swanson, H., Gan, E. \& Bubandt, N. (Eds.). (2017). Arts of living on a damaged planet. Minneapolis: University of Minnesota Press.

Ulloa, A. (2017). Dinámicas ambietales y extractivismos en el s. XXI: ¿Es la época del Antropoceno o del Capitaloceno en América Latina? Desacatos, 54, 58-73.

Urbina, X. (2011). Análisis histórico-cultural del Alerce en la Patagonia septentrional occidental, Chiloé, siglos XVI al XIX. Magallania, 39(2), 57-73. 